AGRICA: Journal of Sustainable Dryland Agriculture, 14 (2): 158-165 (2021)

ISSN-Online: 2715-4955; ISSN-Cetak: 2715-6613

DOI: https://doi.org/10.37478/agr.v14i2.1647

\title{
HUBUNGAN C-ORGANIK TANAH TERHADAP SIFAT FISIK TANAH PADA PERTANAMAN SAWI PAKCOY DI DESA WOLOFEO KECAMATAN DETUSOKO KABUPATEN ENDE
}

\author{
Imaculata Fatima, "Ermelinda Kue, Charly Mutiara, \\ Program studi Agroteknologi, Fakultas Pertanian Universitas Flores \\ Jln. Sam Ratulanggi XX Paupire, Ende, Nusa Tenggara Timur \\ *ermelindakue16@gmail.com
}

\begin{abstract}
Relationship Of C-Organic Soil Towards Physical Properties Of Soil In Pakcoy Palm Planting In Wolofeo Village, Detusoko District, Ende Regency. The production of mustard pakcoy (Brassica rapa L.) depends on the level of soil properties. Therefore, a study was conducted to determine the physical and chemical properties of the soil for mustard cultivation and its relationship. This research is quantitative descriptive. Observation variables in this study were C-organic soil, soil texture, soil moisture content, porosity, and bulk density. Laboratory data from soil physical properties and C-organic soil were matched with soil chemical criteria and evaluation of land suitability, After that, correlation analysis is used to see the relationship. The results showed that the C-organic content of the soil in Wolofeo Village was 3.01\%-3.54\% and was classified as high. While the physical properties of the soil in Wolofeo Village are for soil moisture content ranging from $39.77 \%-41.11 \%$, Porosity ranges from $52.42 \%-61.33 \%$, Fill Density ranges from $1.02-1.26 \mathrm{~g} / \mathrm{cm} 3$, and the soil texture is sandy loam. These criteria are very suitable conditions for the cultivation of mustard greens. The relationship between C-organic soil and soil physical properties shows a significant relationship.
\end{abstract}

Keywords: C-Organic, relationship, soil physical properties, vegetable

\section{PENDAHULUAN}

Sawi pakcoy (Brassica rapa L.) merupakan salah satu jenis tanaman sayuran yang termasuk keluarga kubiskubisan (Brassicaceae). Pakcoy memiliki kandungan gizi yang essensial bagi tubuh manusia. Kerena itu, sayuran ini bernilai ekonomis tinggi (Sangaji, 2017). Menurut hasil wawancara dengan para petani di Desa Wolofeo, produksi sawi sejak tahun 2017 selalu mengalami penurunan. Hal sama terjadi juga pada produksi sawi tahun 2018 hingga tahun 2019. Produksi dan produktivitas sawiyang rendah ini salah satu penyebabnya adalah karena sifat fisik tanah yang mulai rusak. Kerusakan ini disebabkan oleh penggunaan pupuk anoganik yang tinggi dan terus menerus (Prasetyo et al., 2014).

Budidaya sawi pakchoy di Desa Wolofeo hanya mengandalkan pupuk anorganik. Menurut para petani, dalam budidaya sawi, mereka hanya menggunakan pupuk urea. Selain itu dalam membudidayakan tanaman sawi para petani biasanya tidak menerapkan masa berra pada lahan tersebut. Pengolahan lahan dan Penggunaan pupukan organik secara terus 
Fatima: Hubungan C-Organik tanah terhadap sifat fisik tanah pada pertanaman sawi pakcoy

menerus akan berdampak menurunnya kualitas tanah (Juliansyah, 2019).

Budidaya tanaman sawi pakcoy di desa wolofeo, dilakukan secara intensif. Hal ini dapat menyebabkan kerusakan sifat fisik pada tanah. Pengolahan tanah yang intensif mempercepat kehilangan bahan organik, kualtitas tanah menurun dan tingkat kerapatan isi tanah semakin meningkat (Rosyidah \& Wirosoedarmo, 2013).

Menurunnya kualitas tanah, terutama sifat fisik tanah dipengaruhi oleh jumlah bahan organik yang ada. Fungsi bahan organik bagi sifat fisik tanah adalah sebagai pembenah tanah yang berperan dalam perbaikan sifat-sifat tanah baik sifat fisik, kimia dan biologi tanah. Hal ini sejalan dengan kajian dari (Hartatik \& Setyorini, 2012) yang mengatakan bahwa semakin tinggi kandungan C-organik tanah kondisi sifat fisik tanah akan semakin baik.

Lahan yang diolah diolah dengan baik, maka mempengaruhi jumlah dan kualitas bahan organik di dalam tanah. Pada lahan pertanian tanah yang tidak diolah memiliki kandungan C-organik yang lebih tinggi dibandingkan tanah yang diolah secara intensif.

Berdasarkan uraian di atas maka penulis merasa tertarik untuk melakukan penelitian dengan judul "Hubungan Corganik Terhadap Sifat Fisik Tanah Pada Lahan Pertanaman Sawi Pakcoy
(Brassica rapa L.) Di Desa Wolofeo Kecamatan Detusoko Kabupaten Ende".

\section{METODE PENELITIAN}

\section{Tempat dan Waktu Penelitian}

Penelitian ini dilakukan Di Desa WolofeoKecamatan Detusoko Kabupaten Ende. Penelitian ini dilaksanakan selama tiga bulan yaitu dari bulan Mei sampai bulan Juli 2020.

\section{Bahan dan Alat}

Bahan yang digunakan dalam penelitian ini adalah tanah padalahan budidaya sawi pakcoy. Sedangkan peralatan yang digunakan yaitu Cangkul, parang, Meter, kantong plastik, ring sampel, alat tulis dan kamera.

\section{Pelaksanaan Penelitian}

\section{Penentuan Titik Sampel}

Pemilihan lokasi penelitian ditentukan dengan metode purposive sampling, yang di maksud dengan metode purposive sampling adalah pengambilan sampel tanah dengan kriterial tertentu. Kriterial yang digunakan adalah dusundusun yang membudidayakan tanaman sawi pakcoy. Maka di dapatkan 3 dusun dari 4 dusun Di Desa Wolofeo yang menanam tanaman sawi pakcoy.

\section{Teknik Pengambilan Sampel}

Pengambilan sampel tanah menggunakan Teknik pengambilan sampel tanah utuh dan terganggu. Teknik pengambilan tanah terganggu ini dengan 
menggunakan kantong plastik dan diambil lima titik sampel pada lahan secara acak. Setiap titik yang sudah ditentukan digali tanahnya dengan kedalaman $\pm 20 \mathrm{~cm}$. Selanjutnya sampel tanah tersebut, pada setiap perlakuan yang sama dicampur atau dikomposit. Sedangkan Teknik pengambilan sampel tanah utuh menggunakan ring sampel.

\section{Variabel Pengamatan}

Variabel yang diamati adalah Tekstur Tanah, Kadar Air Tanah, Kerapatan Isi, Porositas dan C-organik.

\section{Analisi Data}

Data hasil analisis sifat fisik dan kimia tanah dianalisis dengan Metode
Matching. Data hasil analisis sifat fisik dideskripsikan dengan analisis kesesuaian lahan dari Pusat Penelitin Tanah, dan untuk kandungan C-organik tanah dideskripsikan dengan kriteria kesuburan tanah. Sedangkan untuk melihat hubungan antara variabel dianalisis dengan uji kolerasi.

\section{HASIL DAN PEMBAHASAN}

Sifat fisik tanah telah dianalsis di labarotorium. Hasil analisis dapat dilihat pada Tabel 1 di bawah ini. Sedangkan untuk mengatahui tingkat kesesuaian lahan, dapat dilihat pada Tabel 2.

Tabel 1. Hasil analisis kandungan C-organik Dan Sifat Fisik Tanah

\begin{tabular}{|c|c|c|c|c|c|c|c|c|}
\hline \multirow{2}{*}{ Sampel } & \multirow{2}{*}{$\begin{array}{r}\text { Kadar } \\
\text { Air }(\%)\end{array}$} & \multirow{2}{*}{$\begin{array}{l}\text { C- } \\
\text { org. } \\
\text { (\%) }\end{array}$} & \multirow{2}{*}{$\begin{array}{c}\text { Kerapa } \\
\text { tan Isi } \\
\left(\mathrm{g} / \mathrm{cm}^{3}\right)\end{array}$} & \multirow{2}{*}{$\begin{array}{c}\text { Porosita } \\
\text { s (\%) }\end{array}$} & \multicolumn{3}{|c|}{ KomposisiFraksi (\%) } & \multirow{2}{*}{$\begin{array}{l}\text { Kelas } \\
\text { Tekstur }\end{array}$} \\
\hline & & & & & Pasir & Debu & Liat & \\
\hline Dusun I & & & & & & & & \\
\hline & 39,77 & 3,01 & 1,02 & 61,33 & 77 & 9 & 14 & $\begin{array}{l}\text { Lempung } \\
\text { berpasir }\end{array}$ \\
\hline $\begin{array}{l}\text { Dusun } \\
\text { II }\end{array}$ & 41,11 & 3,54 & 1,26 & 52,42 & 70 & 17 & 13 & $\begin{array}{l}\text { Lempung } \\
\text { berpasir }\end{array}$ \\
\hline $\begin{array}{l}\text { Dusun } \\
\text { III }\end{array}$ & 40,55 & 3,33 & 1,13 & 57,54 & 73,33 & 12,67 & 14 & $\begin{array}{l}\text { Lempung } \\
\text { berpasir }\end{array}$ \\
\hline
\end{tabular}


Fatima: Hubungan C-Organik tanah terhadap sifat fisik tanah pada pertanaman sawi pakcoy

Tabel 2. Tingkat Kesesuaian Lahan

\begin{tabular}{clcc}
\hline Sampel & \multicolumn{1}{c}{$\begin{array}{c}\text { Variabel } \\
\text { Pengamatan }\end{array}$} & Hasil Pengamatan & $\begin{array}{c}\text { Kelas } \\
\text { Kesesuaian } \\
\text { Lahan }\end{array}$ \\
\hline Dusun I & Kadar Air Tanah & $39,77 \%$ & $\mathrm{~S} 1$ \\
& Porositas & $61,33 \%$ & $\mathrm{~S} 1$ \\
& Kerapatan Isi & $1,02 \mathrm{~g} / \mathrm{cm}^{3}$ & $\mathrm{~S} 1$ \\
& Tekstur Tanah & Lempung berpasir & $\mathrm{S} 1$ \\
Dusun & Kadar Air Tanah & $41,11 \%$ & $\mathrm{~S} 1$ \\
II & Porositas & $52,42 \%$ & $\mathrm{~S} 1$ \\
& Kerapatan Isi & $1,26 \mathrm{~g} / \mathrm{cm}^{3}$ & $\mathrm{~S} 1$ \\
& Tekstur Tanah & Lempung berpasir & $\mathrm{S} 1$ \\
Dusun & Kadar Air Tanah & $40,55 \%$ & $\mathrm{~S} 1$ \\
III & Porositas & $57,54 \%$ & $\mathrm{~S} 1$ \\
& Kerapatan Isi & $1,13 \mathrm{~g} / \mathrm{cm}^{3}$ & $\mathrm{~S} 1$ \\
& Tekstur Tanah & Lempung berpasir & $\mathrm{S} 1$ \\
\hline
\end{tabular}

Keterangan: S1: Sangat Sesuai

Data hasil analisis Laboratorium menunjukkan bahwa kondisi sifat fisik tanah yang diambil dari Lahan sawi di dusun 1, 2 dan 3 masuk dalam kategori sangat sesuai untuk tanaman Sawi. Kondisi lahan dengan kategori ini menggambarkan bahwa faktor pembatas yang ada masih dapat ditangani sehingga belum mempengaruhi produksi tanaman (Suheri et al., 2018).

Penilaian kesuaian Lahan yang sangat sesuai ini dilihat dari variabel pengamatan kadar air tanah, porositas, kerapatan isi dan tekstur tanah. Hasil analisis kadar air tanah pada lahan yang membudidayakan tanaman sawi pakcoy dari ketiga dusun di desa Wolofeo adalah 39,77\%, 41,11\%, dan 40,55\%. Kadar air tanah tersebut jika dibandingkan dengan syarat tumbuh bagi tanaman sawi tergolong sangat sesuai (Alifah et al., 2019).

Porositas tanah yang diamati dari tanah-tanah pada ketiga di Desa Wolofeo adalah $61,33 \%, 52,42 \%$, dan $57,54 \%$. Kondisi porositas tanah ini jika dibandingkan dengan syarat tumbuh tanaman sawi maka tergolong kondisi yang ideal (Delsiyanti et al., 2016). Hal ini diperkuat lagi dengan hasil evaluasi kesesuaian lahan yang menunjukan kondisi porositas tanah yang sangat sesuai untuk tanaman sawi (Herman, 2020).

Hasil analisis kerapatan isi tanah pada Lahan yang membudidayakan tanaman sawi pakcoy di dusun 1, 2 dan 3 menunjukkan hasil sebagai berikut: 1,02 $\mathrm{g} / \mathrm{cm}^{3}, 1,26 \mathrm{~g} / \mathrm{cm}^{3}$ dan $1,13 \mathrm{~g} / \mathrm{cm}^{3}$. Kondisi tersebut sangat sesuai untuk tanaman sawi pakcoy. Hasil penelitian yang mendukung 
hal ini adalah hasil penelitian dari (Ariadna et al., 2019) yang menyatakan bahwa kerapatan isi lahan-lahan pertanian berkisar antara1,17-1,52 gr/ $\mathrm{cm}^{3}$.

Kondisi sifat Fisik lainnya yang menggambarkan kondisi tanah yang sangat sesuai untuk budidaya tanaman sawi pakcoy adalah tekstur tanah. Hasil analisis Laboratorium pada tanah-tanah yang membudidayakan tanaman sawi pakcoy di dusun 1, 2, dan 3 dari Desa Wolofeo adalah lempung berpasir. Tekstur ini sangat sesuai untuk tanaman sawi karena tanaman sawi menghendaki kondisi tanah dengan kelas tekstur lempung berpasir (Astuti et al., 2013).

\section{C-Organik Tanah}

Hasil analisis C-organik tanah dengan metode Walkey and black telah dilakukan. Analisis tersebut diambil dari lahan sawi di tiga dusun. Hasil analisis dapat dilihat pada Tabel 3 di bawah ini.

Tebel 3. C-Organik Tanah

\begin{tabular}{ccccc}
\hline Sampel & $\begin{array}{c}\text { Variabel } \\
\text { Pengamatan }\end{array}$ & $\begin{array}{c}\text { Hasil } \\
\text { Analisis }\end{array}$ & $\begin{array}{c}\text { Kriteria } \\
\text { Kimia } \\
\text { Tanah }\end{array}$ & $\begin{array}{c}\text { Evaluasi } \\
\text { Kesesuain } \\
\text { Lahan }\end{array}$ \\
\hline Dusun I & C-organik & $3,01 \%$ & $\mathrm{~T}$ & $\mathrm{~S} 1$ \\
DusunII & C-organik & $3,54 \%$ & $\mathrm{~T}$ & $\mathrm{~S} 1$ \\
Dusun III & C-organik & $3,33 \%$ & $\mathrm{~T}$ & $\mathrm{~S} 1$ \\
\hline
\end{tabular}

Keterangan: T: Tinggi, S1:Sangat sesuai

Kandungan C-organik tanah pada lahan budidaya tanaman sawi pakcoy didesa Wolofeo adalah 3,01-3,54\% dan termasuk pada kriteria tinggi. Kandungan C-Organik yang tinggi ini dapat terjadi karena tanah yang digemburkan terus menerus memiliki proses dekomposisi yang lebih cepat. Hal ini disebabkan oleh aerasi pada tanah yang diolah menjadi lebihbaik sehingga mikroorganisme akan tumbuh baik dan cepat sehingga proses dekomposisi akan berjalan lebih cepat pada tanah yang diolah dibanding dengan tanah yang tidak diolah (Hanafiah, 2012).
Kondisi C-organik tanah pada Lahan yang membudidayakan tanaman sawi pakcoy di Desa Wolofeo juga tergolong sangat sesuai berdasarkan evaluasi kesesuaian Lahan. Keberadaan C-organik dalam tanah yang tinggi memberikan dampak positif bagi perbaikan sifat Fisik tanah. Hal ini dapat terjadi karena ikatanikatan partikel tanah akan menjadi lebih baik ketika adanya bahan-bahan organik yang berfungsi sebagai perekat (Saridkk, 2017). 
Fatima: Hubungan C-Organik tanah terhadap sifat fisik tanah pada pertanaman sawi pakcoy

Hubungan C-Organik dengan Sifat Fisik Tanah

Hubungan C-organik dan sifat-sifat

fisik tanah telah dilakukan. Hasil analisis tersebut dapat dilihat pada tabel 4 di bawah ini.

Tabel 4 Hubungan C-Organik dengan Sifat Fisik Tanah

\begin{tabular}{cccccc}
\hline No & $\begin{array}{c}\text { Variabel } \\
\text { Bebas }\end{array}$ & $\begin{array}{c}\text { Variabel } \\
\text { Terikat }\end{array}$ & $\begin{array}{c}\text { R } \\
\text { Square }\end{array}$ & $\begin{array}{c}\text { Variabel } \\
\mathbf{r d a n} \mathbf{x}\end{array}$ & Kriteria \\
\hline 1 & C-Organik & Porositas & 0,958 & 1 & Sangat Kuat \\
2 & C-Organik & $\begin{array}{c}\text { Kadar Air } \\
\text { tanah } \\
\text { Pasir }\end{array}$ & 0.999 & 1 & Sangat Kuat \\
3 & C-Organik & 0.992 & 1 & Sangat Kuat \\
4 & C-Organik & Debu & 0.054 & -1 & $\begin{array}{c}\text { Sangat } \\
\text { Rendah } \\
\text { Kuat }\end{array}$ \\
5 & C-Organik & Liat & 0.641 & -1 & Sangat Kuat \\
6 & C-Organik & $\begin{array}{c}\text { Kerapatan } \\
\text { Isi }\end{array}$ & 0.972 & 1 & \\
\hline
\end{tabular}

Hasil analisis korelasi yang digunakan untuk melihat hubungan antara C-organik tanah dengan Sifat Fisik tanah sebesar 0,999 hubungan yang sangat kuat hampir semua hubungan antara variabel. Kondisi ini sejalan dengan hasil penelitian yang dilakukan (Surya et al., 2017).

Selain itu hubungan antara C-organik tanah pada Lahan yang membudidayakan tanaman sawi pakcoy dengan kadar air tanah juga menunjukkan hubungan yang sangat kuat. Hal ini terjadi karena kandungan C-organik tanah berperan untuk menahan air tanah sehingga tidak mudah hilang (Hanafiah, 2012).
Hasil uji korelasi antara C-Organik tanah dengan partikel-partikel pada tekstur tanah menunjukkan hasil yang sangat kuat kecuali dengan partikel debu. Hubungan Corganik tanah yang sangat kuat dengan tekstur tanah ini dapat terjadi karena bahan organik berperan sebagai penstabil agregat tanah. Dengan adanya bahan organic ini, maka ikatan-ikatan tanah menjadi lebih baik sehingga komposisi tanah menjadi lebih gembur.

\section{SIMPULAN}

Kesimpulan dari penelitian ini adalah kandungan C-organik tanah di desaWolofeoadalah3,01\%-3,54

$\%$ dantergolongtinggi. Sedangkan sifat fisik 
tanah di Desa Wolofeoadalahuntuk Kadar Air tanah berkisar antara 39,77\%-41,11\%, Porositas berkisar antara 52,42\%-61,33\%, Kerapatan Isi berkisar antara 1,02 -1,26 $\mathrm{g} / \mathrm{cm}^{3}$,dan tekstur tanah adalah lempung berpasir. Kriteria tersebut merupakan kondisi yang sangat sesuai untuk budidaya tamanan Sawi. Dari hasil analisis korelasi diketahui bahwa hubungan C-organik tanah dan sifat fisik tanah adalah kuat.

\section{Ucapan Terimakasih}

Penelitian ini dapat dilaksanakan karena adanya beberapa pihak yang mendukung kami, untuk itu perkenankanlah kami menyampaikan ucapan terimakasih kepada Pimpinan Fakultas Pertaniandan Program Studi yang telah memberikan masukan, kritik dan saran kepada penulis serta semua pihak yang telah membantu penelitian dan penyelesaian penulisan artikel ini.

\section{DAFTAR PUSTAKA}

Alifah, S., Nurfida, A., \& Hermawan, A. (2019). Pengolahan Sawi Hijau Menjadi Mie Hijau Yang Memiliki Nilai Ekonomis Tinggi Di Desa Sukamanis Kecamatan Kadudampit Kabupaten Sukabumi. Journal of Empowerment Community, 1(2), 52$58 . \quad$ https://ejournal.unper.ac.id/index.php/JEC/arti cle/view/364/297

Ariadna, Aisyah, \& Saleh. (2019). Permukaan Pembasahan Irigasi Kendi Pada Tiga Jenis Tanah Dan Kerapatan Isi Berbeda [Sriwijaya University]. https://repository.unsri.ac.id/2173/
Astuti, U. P., Wahyuni, T., \& Honorita, B. (2013). Petunjuk Teknis Budidaya Sayuran di Lahan Pekarangan. In Balai Pengkajian Teknologi Pertanian (Vol. 26, Issue 4). Balai Pengkajian Teknologi Pertanian.

Badan Pusat Statistik. (2013). Hasil Produksi dan Produktifitas Sayuran di Indonesia.

Delsiyanti, Widjajanto, D., \& Rajamuddin, U. A. (2016). Sifat Fisik Tanah Pada Beberapa Penggunaan Lahan di Desa Oloboju Kabupaten Sigi. Jurnal Agrotekbis, 4(3), 227-234. http://jurnal.faperta.untad.ac.id/index. php/agrotekbis/article/view/13/8

Hanafiah, K. . (2012). Dasar-Dasar Ilmu Tanah. PT Raja Grafindo Persada.

Hartatik, W., \& Setyorini, D. (2012). Pemanfaatan Pupuk Organik untuk Meningkatkan Kesuburan Tanah dan Kualitas Tanaman. Peneliti Badan Litbang Pertanian, 12, 571-582. https://balittanah.litbang.pertanian.go.i d/ind/dokumentasi/lainnya/52 - Wiwik Hartatik dan Diah Setyorini Pemanfaatan Pupuk Organik untuk Meningkatkan Kesuburan Tanah.pdf

Herman, W. (2020). Pemanfaatan Biochar Plus Terhadap Tanah Entisol Pesisir Pantai Dan Tanaman Sawi Hijau (Brassica juncea L.). Jurnal Galung Tropika, 9(1), 68-74. https://doi.org/http://dx.doi.org/10.318 50/jgt.v9i1.556

Juliansyah, M. I. (2019). Pengaruh Pupuk Hayati Mikoriza - Trikoderma dan Pengurangan Dosis Pupuk Anorganik Terhadap Beberapa Sifat Fisik Tanah Pada Budidaya Kubis Bunga(Brassica Oleracea) [Universitas Jenderal Soedirman]. http://repository.unsoed.ac.id/4371/

NURMEGAWATI, AFRIZON, \& SUGANDI, D. (2020). Kajian Kesuburan Tanah Perkebunan Karet Rakyat Di Provinsi Bengkulu. Jurnal Penelitian Tanaman Industri, 20(1), 17. https://doi.org/10.21082/jlittri.v20n1.2 
Fatima: Hubungan C-Organik tanah terhadap sifat fisik tanah pada pertanaman sawi pakcoy

014.17-26

Prasetyo, A., Listyorini, E., \& Utomo, W. H. (2014). Hubungan Sifat Fisik Tanah, Perakaran dan Hasil Ubi Kayu Tahun Kedua pada Alfisol Jatikerto Akibat Pemberian Pupuk Organik dan Anorganik. Jurnal Tanah Dan Sumber Daya Lahan, 1(1), 27-37.

Roidah, I. S. (2013). Manfaat Penggunaan Pupuk Organik Untuk Kesuburan Tanah. Universitas Tulungagung BONOROWO, 1(1), 30-42. https://doi.org/https://doi.org/10.36563 /bonorowo.v1i1.5

Rosyidah, E., \& Wirosoedarmo, R. (2013). Pengaruh sifat fisik tanah pada konduktivitas hidrolik jenuh di 5 penggunaan lahan. Agritech, 33(3), 340-345.

https://doi.org/https://doi.org/10.22146 /agritech.9557

Sangaji, Z. T. S. di P. K. M. D. A. K. S. (2017). Kajian Sistem Budidaya. Median Volume, IX(1), 16-24. https://ejournal.um-

sorong.ac.id/index.php/median/article/ viewFile/312/142

Sari, M. N., Sudarsono, \& Darmawan. (2017). Pengaruh Bahan Organik Terhadap Ketersediaan Fosfor pada Tanah-Tanah Kaya Al dan Fe. Buletin Tanah Dan Lahan, 1(1), 65-71.

Suheri, N. A., Mujiyo, M., \& Widijanto, H. (2018). Land Suitability Evaluation for Upland Rice in Tirtomoyo District, Wonogiri Regency, Indonesia. SAINS TANAH - Journal of Soil Science and Agroclimatology, $\quad 15(1), \quad 46$. https://doi.org/10.15608/stjssa.v15i1.2 1670

Surya, J. A., Nuraini, Y., \& Widianto. (2017). Study of Soil Porosity in Providing Several Types of Organic Materials in Robusta Coffee Plantation. Journal of Soil and Land Resources, 4(1), 463-471. https://jtsl.ub.ac.id/index.php/jtsl/articl e/view/160 